\title{
Adverse Effects of Rice gall dwarf virus upon its Insect Vector Recilia dorsalis (Hemiptera: Cicadellidae)
}

Yong Chen, Chengcong Lu, Manman Li, and Wei Wu, Fujian Province Key Laboratory of Plant Virology, Institute of Plant Virology, Fujian Agriculture and Forestry University, Fuzhou, Fujian 350002, PR China; Guohui Zhou, College of Agriculture, South China Agricultural University, Guangzhou, Guangdong 510642, China; and Taiyun Wei, Fujian Province Key Laboratory of Plant Virology, Institute of Plant Virology, Fujian Agriculture and Forestry University

\begin{abstract}
Chen, Y., Lu, C., Li, M., Wu, W., Zhou, G., and Wei, T. 2016. Adverse effects of Rice gall dwarf virus upon its insect vector Recilia dorsalis (Hemiptera: Cicadellidae). Plant Dis. 100:784-790.

Rice gall dwarf virus (RGDV), a plant reovirus that threatens rice production in Southeast Asia and Southern China, is transmitted by the leafhopper vector Recilia dorsalis in a persistent-propagative manner. To assess the direct effects of RGDV on $R$. dorsalis, we established an infected leafhopper population from eggs laid by viruliferous females using the water-soaked filter paper culture method. Life history parameters indicated that the virus was harmful to its vector in terms of all biotic indices, including reduced survival rate, emergence rate, fecundity, and longevity of adults, compared with a nonviruliferous control population. Those findings were supported by systematic monitoring of

viruliferous rates of $R$. dorsalis in different overwintering generations. To better elucidate the adverse effects of RGDV on its vector, we measured fecundity at the molecular level using quantitative reversetranscription polymerase chain reaction and Western blot assays, which revealed differential expression of vitellogenin $(\mathrm{Vg})$ in viruliferous versus nonviruliferous adult females. We infer that RGDV reduced levels of $\mathrm{Vg}$ transcript and protein product, resulting in the lower fecundity of its vector. Overall, this study demonstrates how RGDV exerts an adverse effect on $R$. dorsalis, which hinders the expansion of viruliferous populations of the insect.
\end{abstract}

Many viral pathogens that cause significant global health and agricultural problems are transmitted via insect vectors. To maximize their rates of transmission, plant viruses may influence the biology and behavior of their vectors. Plant viruses may manipulate their insect vectors as a result of direct interaction with the insects or via indirect changes due to the sap components in the infected host plants (Belliure et al. 2005; Hogenhout et al. 2008; Navas-Castillo et al. 2011). The persistent-propagative plant viruses have evolved to be well adapted for persistent infection and maintenance in their insect vectors, and may exhibit some characteristics of insect pathogens (Chen et al. 2013, 2014a; Mao et al. 2013; Whitfield et al. 2015). Because nonpersistent, semipersistent, and persistent-nonpropagative plant viruses do not replicate within the vector's body, it has been suggested that their effects on the vector's fitness are probably mainly indirect (i.e., through changes in infected plant hosts), whereas the effects of persistent-propagative plant viruses, which replicate within the vector's tissues, may be both direct and indirect (Hogenhout et al. 2008; Whitfield et al. 2015).

The propagation of plant viruses in insect vectors has long been believed to be detrimental to the insect host. For example, the plant reovirus Southern rice black-streaked dwarf virus (SRBSDV) is harmful to its vector Sogatella furcifera (white-backed planthopper, WBPH) with respect to all life history parameters (Tu et al. 2013; Xu et al. 2014; Zhang et al. 2014). The replication of Impatiens necrotic spot virus, a tospovirus, revealed similar adverse effects on its vector Frankliniella occidentalis (Deangelis et al. 1993). Indeed, the

Corresponding authors: T. Wei; E-mail: weitaiyun@fafu.edu.cn; and G. Zhou; E-mail: ghzhou@ @scau.edu.cn

*The $\boldsymbol{e}$-Xtra logo stands for "electronic extra" and indicates that one supplementary figure is published online.

Accepted for publication 5 November 2015.

http://dx.doi.org/10.1094/PDIS-06-15-0713-RE

This article is in the public domain and not copyrightable. It may be freely reprinted with customary crediting of the source. The American Phytopathological Society, 2016. propagation of plant viruses has been shown to manipulate vector behavior to the advantage of the viruses by inducing deceptive visual or chemical cues to attract vectors to promote virus spread. For example, SRBSDV-infected plants were more attractive to nonviruliferous WBPH individuals than viruliferous ones, whereas healthy plants were more attractive to the viruliferous compared with nonviruliferous individuals (Wang et al. 2014). These changes in the biology and behavior of vectors that occur after they feed on virus-infected plants could be attributed to direct effects of the acquired virus on the vector; however, such direct effects are difficult to distinguish from indirect effects associated with feeding on virus-infected plants. Thus, horizontal transmission of plant viruses from insect to insect through plant hosts may indirectly affect vector physiology and behavior (Belliure et al. 2005; Fereres et al. 1989; Fiebig et al. 2004; Jiu et al. 2007; Luan et al. 2013; McKenzie 2002; Ng and Falk 2006; Rubinstein and Czosnek 1997; Tu et al. 2013; Wang et al. 2014). In fact, some persistent-propagative plant viruses, including rhabdoviruses, tenuiviruses, and reoviruses, are also transmitted vertically from mother to offspring (Hogenhout et al. 2008). Previous studies found that Rice stripe virus (RSV, a tenuivirus) and Rice dwarf virus (RDV, a plant reovirus) reduced the viability of their vectors' offspring, suggesting that transovarially transmitted viruses may directly affect their insect vectors ( $\mathrm{Li}$ et al. 2015; Nakasuji and Kiritani 1970). Clearly, there is a trade off between a limited damage of viral infection on insects and an effective transmission of viruses to plant hosts by insect vectors in nature. For example, plant virus infection can accelerate vitellogenesis of its vector insect and thereby increase its fecundity via their shared host plant (Guo et al. 2012). In addition, the strategy of maternal inheritance could counteract the adverse effects of RSV and RDV on the insect vectors to promote viruses spread ( $\mathrm{Li}$ et al. 2015; Nakasuji and Kiritani 1970).

In this study, we used the system of Rice gall dwarf virus (RGDV), a plant reovirus, and its leafhopper vector Recilia dorsalis (Hemiptera: Cicadellidae) to determine how the propagation of a plant virus directly affects the biology of its insect vector. RGDV is transmitted mainly by $R$. dorsalis in a persistent-propagative manner and via maternal inheritance (Fan et al. 1983; Inoue and Omura 1982; Morinaka et al. 1982; Xie and Lin 1984). RGDV was first described in 1979 in Thailand. The characteristic symptoms in rice include dark green 
discoloration of the leaf blades, severe stunting of the plants, and gall along the leaf blades and leaf sheaths, which cause substantial yield loss (Omura et al. 1980) in Southern China and Southeast Asia. Over the past several years, RGDV has spread to Guangdong, Hainan, and Guangxi Provinces of Southern China. To exclude possible effects of any changes in vector physiology and behavior after viral acquisition through feeding on diseased plants, we established RGDV-infected progeny from eggs laid by viruliferous females of $R$. dorsalis. Thus, the virus was passed from insect to insect through the eggs, with only the original females in the experiment having access to virus-infected plants. In this way, we provide experimental evidence that a plant virus infection passed through maternal inheritance, which eliminates the indirect effects from infected plant hosts, could directly alter the fitness of its insect vector. These findings enhance our knowledge of viral impacts on insect vectors, with implications for better strategies to disrupt the efficiency of viral transmission in the future.

\section{Materials and Methods}

Rearing of plants, virus, and insects. Rice (Oryza sativa) 'Taichung Native 1' (TN-1) was used in this study. Water planting of rice was conducted according to Yoshida et al. (1976). The RGDV isolate was collected from infected field rice in Xingning County, Guangdong Province, China during the 2013 growing season, and its identity was confirmed by reverse-transcription polymerase chain reaction (RT-PCR). The virus was transmitted to $\mathrm{TN}-1$ rice plants using $R$. dorsalis following the methods of Wang et al. (2014).

$R$. dorsalis adults were collected from healthy field plants in Xingning, Guangdong Province, China. They were propagated on healthy TN-1 plants grown in insect-proof greenhouses at $25 \pm$ $1{ }^{\circ} \mathrm{C}$, under conditions of $75 \pm 5 \%$ relative humidity and a photoperiod of $16 \mathrm{~h}$ of light and $8 \mathrm{~h}$ of darkness. To ensure that the insects were RGDV free, offspring (second generation) of the original individuals collected in the field that were confirmed RGDV negative in RT-PCR detection were reared on healthy rice plants that were replaced daily. From this population, one pair (consisting of a newly emerged male and female from the second-generation) was placed on a healthy plant and left to mate and reproduce; they were kept for 12 days, with seedlings replaced daily. Then, 40 of their offspring (third generation) were selected and raised on healthy rice seedlings that were replaced daily to mate and reproduce, and their offspring (fourth generation) were used as the nonviruliferous population. To ensure that the insects were RGDV free, offspring (second and third generations) and the rice plants used to rear the nonviruliferous population were confirmed to be RGDV negative in RT-PCR detection.

To establish a viruliferous population, 40 of the first-instar nymphs of $R$. dorsalis (third generation) were contained for 2 days on RGDVinfected rice stems that had been inoculated at the tillering stage, with infection confirmed by RT-PCR. Then, the leafhoppers were raised on healthy rice seedlings that were replaced daily. After emergence, pairs (consisting of one female and one male viruliferous leafhopper) were placed in glass tubes $(3 \mathrm{~cm}$ in diameter by $15 \mathrm{~cm}$ in length) that contained a single rice seedling; they were kept for 12 days, with seedlings replaced daily. Leafhoppers were then tested individually for viral infection by RT-PCR. Eggs were removed from seedlings in the glass tubes that harbored pairs of leafhoppers (i.e., from pairs that tested RGDV positive), and placed individually on pieces of water-soaked filter paper (Fig. 1). Each paper along with the egg was placed in a new glass tube with one healthy rice seedling. After eclosion, the rice seedlings were replaced every day. The eggs or nymphs from viruliferous females were used as the viruliferous population.

Effects of RGDV on life history parameters of $\boldsymbol{R}$. dorsalis. To determine the effects of RGDV on $R$. dorsalis growth, 50 firstinstar nymphs of $R$. dorsalis from the viruliferous population were carefully transferred with a vacuum device into individual culture tubes containing one healthy rice seedling, which was replaced daily. At the same time, 50 nonviruliferous insects were used as a control population, maintained in tubes under the same conditions. Growth of leafhoppers in each tube was monitored at 12-h intervals until the end of adult life. Duration of each developmental stage was recorded individually. All the nymphs and adults were subjected to
RT-PCR assays after death. The entire experiment was repeated three times.

To examine the effects of RGDV on $R$. dorsalis, life history parameters were determined using life tables constructed with the method of Chen et al. (2014b). For each sample, 100 viruliferous nymphs were collected randomly and reared on the healthy rice seedlings under the conditions described above, with rice seedlings replaced daily. When the nymphs developed into fifth-instar nymphs, the survival rate was calculated as $\mathrm{Su}_{1-5}$. The emerged males and females were then counted daily to determine the emergence rate (Emr) and percentage of females (Fr). The rice seedlings used to feed adults were inspected thoroughly and nonhatched eggs were counted. The copulation rate $(\mathrm{Cr})$ was based on whether the female produced eggs that hatched. The female fecundity (Fy) was based on the average number of eggs laid by females that had copulated. The eclosion rate (Ecr) was based on the total number of nymphs versus the total number of nymphs plus the number of nonhatched eggs. The control was 100 nonviruliferous nymphs, and this experiment was also conducted with three replications. The population growth index (I) was calculated as $\mathrm{Nt}=\mathrm{No} \times \mathrm{Su}_{1-5} \times \mathrm{Emr} \times \mathrm{Fr} \times \mathrm{Cr} \times \mathrm{Fy} \times \mathrm{Ecr}$; $=\mathrm{Nt} / \mathrm{No}$, where No is the number of individuals in the initial population and $\mathrm{Nt}$ is the number of individuals in the next generation.

Effects of RGDV on the fecundity of $\boldsymbol{R}$. dorsalis. To determine how the virus affected fecundity of its leafhopper vector, 50 viruliferous nymphs were collected randomly and reared on healthy seedlings in glass tubes, exactly as described above; 50 nonviruliferous leafhoppers were used as a control. After emergence, 20 pairs (10 pairs of viruliferous and 10 pairs of nonviruliferous insects) consisting of one newly emerged female and one newly emerged male were selected to enable oviposition. They were placed in glass tubes with single rice seedlings that were replaced daily. The number of eggs laid by the female was recorded after the seedlings were replaced. The experiment was conducted with three replications.

To measure vitellogenin $(\mathrm{Vg})$ expression levels in $R$. dorsalis at different time intervals since molting, a real-time quantitative PCR (RT-qPCR) assay was conducted in a Mastercycler Realplex4 realtime PCR system (Eppendorf) using a SYBR Green PCR Master

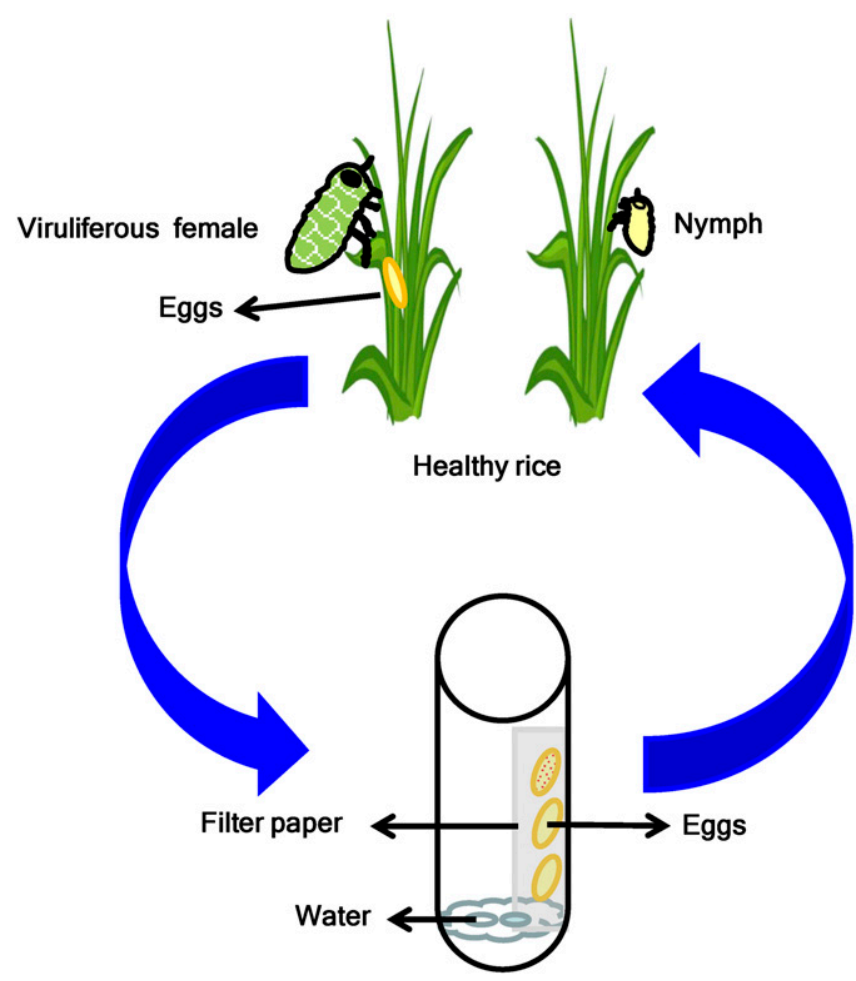

Fig. 1. Diagrammatic illustration of a water-soaked filter paper culture method used to establish a Rice gall dwarf virus-infected Recilia dorsalis population via maternal inheritance. 
Mix kit (Promega Corp.) according to standard protocols. The $\beta$-actin gene of $R$. dorsalis was used as the internal control. To obtain the $\mathrm{Vg}$ sequence in the transcriptome of $R$. dorsalis, we used a local BLASTN search with sequence of Nilaparvata lugens (AB353856.1) as queries. The obtained gene sequence for $\mathrm{Vg}$ of $R$. dorsalis was deposited in GenBank with accession number KT892949. Primers for the target $\mathrm{Vg}$ sequence and endogenous control $\beta$-actin were as follows: $\mathrm{Vg}$ sense AAGTTTTCAGAGGACAACAGTT and antisense TCTTGA GGAGCGGTGAAGTC; $\beta$-actin sense AGAAGTCCTACGAGTTG CCTGATG and antisense TTCATGATGGAGTTGTAGACGGTC (Chen et al. 2015). Total RNA was isolated from the whole-body samples using Trizol reagent (Invitrogen) and treated with DNase I (TaKaRa), and $1 \mu \mathrm{g}$ of RNA was reverse-transcribed in a $10-\mu 1$ reaction system using the AMV RNA PCR Kit (TaKaRa). According to the manufacturer's protocol, each qPCR included $2 \mu \mathrm{l}$ of cDNA template (10-fold dilution), $0.4 \mu$ l of each primer $(10 \mu \mathrm{M}), 0.4 \mu \mathrm{l}$ of Rox Reference Dye, and $10 \mu \mathrm{l}$ of SYBR Green PCR Master Mix kit (Promega Corp.) in a total volume of $20 \mu \mathrm{l}$. The PCR procedure was one cycle at $95^{\circ} \mathrm{C}$ for $30 \mathrm{~s}$, followed 40 cycles of $95^{\circ} \mathrm{C}$ for $5 \mathrm{~s}$ and $60^{\circ} \mathrm{C}$ for $30 \mathrm{~s}$. The relative quantitative method was used to evaluate the

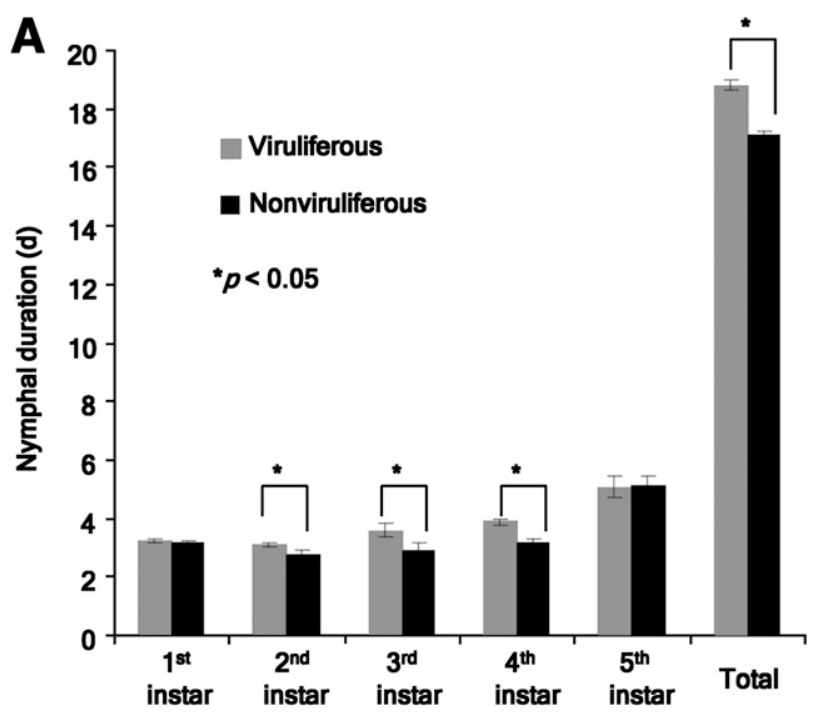

B

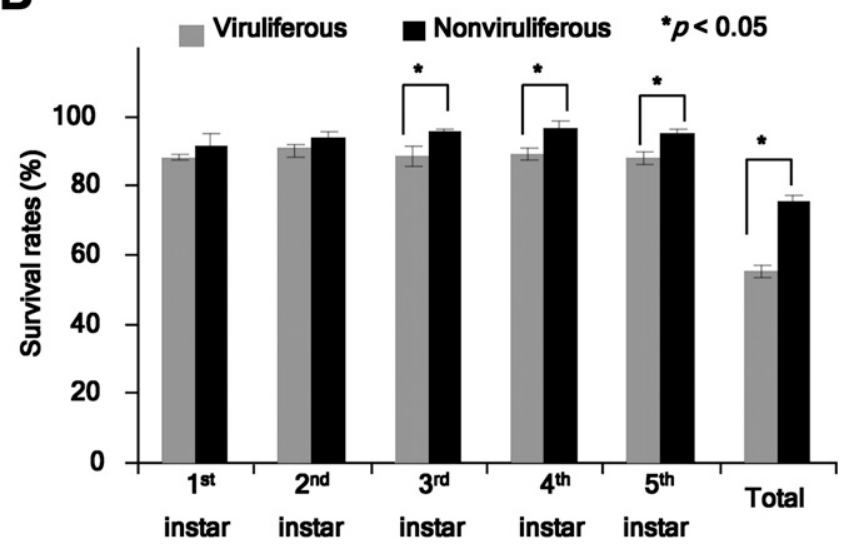

Fig. 2. Direct effects of Rice gall dwarf virus (RGDV) on the duration and survival rates of viruliferous versus nonviruliferous Recilia dorsalis nymphs. Each histogram bar represents the mean ( \pm standard error) of three replicates; means were compared using Tukey's honestly significant difference test (at the level $P=$ 0.05). A, Nymphal stages. One-way analysis of variance (ANOVA): first instar, $F=0.319$, df $=4, P=0.602$; second instar, $F=37.496, \mathrm{df}=4, P=0.004$; third instar, $F=48.978, \mathrm{df}=4, P=0.004$; fourth instar, $F=149.663$, df $=4, P=$ 0.000; fifth instar, $F=0.034, \mathrm{df}=4, P=0.863$; total, $F=91.53$, df $=4, P=$ 0.001 . B, Survival rates of nymphs. One-way ANOVA: first instar, $F=3.384$, $\mathrm{df}=4, P=0.14$; second instar, $F=1.73$, df $=4, P=0.259$; third instar, $F=$ 17.459, df $=4, P=0.014$; fourth instar, $F=23.06, \mathrm{df}=4, P=0.009$; fifth instar, $F=31.291, \mathrm{df}=4, P=0.005 ;$ total, $F=236.944, \mathrm{df}=4, P=0.000$. quantitative variation; that is, $2^{-\Delta \Delta \mathrm{Ct}}: 2^{\wedge}\left[-\left(\mathrm{Ct}_{\text {target }}-\mathrm{Ct}_{\mathrm{actin}}\right)_{\text {time } x}-\right.$ $\left.\left(\mathrm{Ct}_{\text {target }}-\mathrm{Ct}_{\text {actin }}\right)_{\text {time } 0}\right]$, where $\mathrm{Ct}$ is the cycle threshold, time $x$ is any time point, and time 0 represents the $1 \times$ expression of the target gene normalized to actin).

A Western blot assay was used to confirm the above results. Rabbit polyclonal antiserum against $\mathrm{Vg}$ was prepared as follows. The $\mathrm{Vg}$ genes from an $R$. dorsalis population from Guangdong Province, China were amplified by RT-PCR (Vg sense $5^{\prime}$-AGGCTTCGAAG TTTTCAGAGGACAACAGTT-3' and antisense 5'-TGGGTCGTC TTGAGGAGCGGTGAAGTC-3'), and the products were purified and engineered into Gateway vector pDEST17 (Invitrogen). The resulting Vg plasmids were then used to transform Escherichia coli strain Rosetta (DE3) and expressed by adding isopropyl$\beta$-D-thiogalactopyranoside $(1 \mathrm{mmol} / \mathrm{liter}$; Sigma). Cells were harvested and sonicated. The final suspension of $\mathrm{Vg}$ protein was purified with nickel-nitrilotriacetic acid resin (Qiagen), and rabbits were immunized with the purified proteins. Anti-His-Vg serum was prepared using a method described previously (Jia et al. 2012). The antitarget-gene serum could then be used for immunoassays. At 7 days postemergence, the proteins of the adult female $(n=30)$ were prepared as described previously (Wu et al. 2012).

Monitoring of the overwintering viruliferous rate of $R$. dorsalis in Guangdong. To evaluate the adverse effects of RGDV on $R$. dorsalis in the farmland ecosystem, we investigated variation in the overwintering rate of viruliferous individuals (viruliferous rate [VR]) across generations. Continuous monitoring of the VR of overwintering survival in the first and second generations of field populations from two counties (Luoding and Xingning) in Guangdong Province was conducted in 2013 and 2014. In each survey (the time spacing of the adjacent surveys is about 45 days), at least 1,500 leafhoppers per county were collected from at least 15 rice fields, using a chessboard sampling method. The VR (about 50\% insect samples) was detected using the RT-PCR method, and the VR in each county was calculated using the weighted average algorithm based on the data from each rice field.

Virus detection by RT-PCR. The RGDV P8 sequence searched from National Center for Biotechnology Information databases (number DQ354069.1) and the primers used to target the RGDV P8 sequence were as follows: RGDV P8 sense 5'-ATGTCGCGC CAAGCTTG-3' and RGDV P8 antisense 5'-CTCAGTCAAAG TGTTCATCGACT-3' (amplicon size $=798$ bp). Total RNA was extracted and first-strand cDNA was synthesized as described above. The PCR system included the following: $2 \mu$ of cDNA template, $2.5 \mu l$ of $10 \times$ PCR buffer $\left(\mathrm{Mg}^{+}\right), 2 \mu l$ of dNTP $(2.5 \mathrm{mM}), 0.5 \mu l$ of each primer $(20 \mu \mathrm{M}), 0.125 \mu \mathrm{l}$ of $(2 \mathrm{U})$ TaqDNA polymerase (TaKaRa), and $17.4 \mu \mathrm{l}$ of double-distilled $\mathrm{H}_{2} \mathrm{O}$. The PCR conditions were as follows: one cycle of predenaturing at $94^{\circ} \mathrm{C}$ for $3 \mathrm{~min}$; followed by 30 cycles of denaturing at $94^{\circ} \mathrm{C}$ for $30 \mathrm{~s}$, annealing at $55^{\circ} \mathrm{C}$ for $45 \mathrm{~s}$, and extension at $72^{\circ} \mathrm{C}$ for $1 \mathrm{~min}$; with a final 10 -min extension at $72^{\circ} \mathrm{C}$. The PCR products were resolved on a $1 \%$ agarose gel (Biowest) and visualized by staining with ethidium bromide (Sigma).

Statistical analysis. All data were analyzed with SPSS (version 17.0; SPSS). Percentage data were arcsine square-root transformed before the analysis, as appropriate (Zar 1996). Between-group comparisons were performed by using one-way analysis of variance (ANOVA) for the duration of nymphal stage, survival rate of nymphal stage, longevity of adults, mortality rate of adults, eggs laid by the female, and relative transcript level of Vg. Overwintered generation VR comparison used repeated-measure ANOVA with group-VR interaction. The data were back-transformed after analysis for presentation in the text, figures, and tables.

\section{Results}

Direct effects of RGDV on $R$. dorsalis nymph development and survival of nymphs. The duration of nymphal stages of viruliferous populations were $3.22,3.06,3.58,3.87,5.06$, and 18.79 days for the first, second, third, fourth, and fifth instars and the total nymphal period, respectively; these values were 1.01-, 1.12-, 1.24-, 1.22-, 0.99-, and 1.12-fold compared with the nonviruliferous controls, respectively (Fig. 2A). Thus, viral infection was able to directly prolong 
the nymphal stages of the insect vector. However, the viruliferous population had approximately $19.5 \%$ lower survival rates versus the control across the whole nymphal period (Fig. 2B). Furthermore, the adult emergence rate of the viruliferous population was approximately $12.6 \%$ lower than that of the control (Table 1 ). All these results suggested that the viral infection of leafhoppers negatively influenced nymph survival.

Direct effects of RGDV on adult longevity. The mean longevity of the viruliferous population (18.3 days) was about 12.5 days shorter than that of the nonviruliferous population (30.8 days; Fig. 3A). The mortality curves demonstrated that the individuals in either population started to die at approximately 5 days of age but the mortality rate of viruliferous insects was 2.2 times higher (Fig. 3B). At the population level, the difference between the two types at the $50 \%$ mortality point was about 12 days: 15 days for viruliferous versus 27 days for nonviruliferous (Fig. 3B). These results suggested that life expectancy was significantly lower in the viruliferous population $(F=$ 59.417, $\mathrm{df}=4, P=0.002$ ). Thus, RGDV infection adversely affected adult longevity of its insect vector.

Direct effects of RGDV on adult fecundity. Comparison of the fecundity between the two populations showed that there was a trend for an ascending-descending pattern in the mean number of eggs laid by both viruliferous and nonviruliferous insects (Fig. 4A). However, the preoviposition periods of viruliferous females ( 3 days after emergence) were about 1 day shorter than those of the nonviruliferous females (Fig. 4A). On the other hand, during the period from 7 to 16 days after emergence, viruliferous insects laid significantly fewer eggs $(F=11.264, \mathrm{df}=4, P=0.028$; Fig. 4A). Because of the shorter longevity of viruliferous females, the oviposition period was also considerably shortened, and the viruliferous females laid about $44 \%$ fewer eggs compared with control females (Table 1). Thus, in one generation, the population increased 13.5 times for viruliferous versus 38.4 times for nonviruliferous leafhoppers. Our results indicated that RGDV infection directly hindered expansion of the $R$. dorsalis population.

Comparison of the $\mathrm{Vg}$ transcript levels after emergence between the two populations showed that the levels of Vg transcript in the two types of females increased rapidly up to 9 days after emergence and then began to decrease (Fig. 4B). The relative Vg transcript level of the viruliferous population was reduced by 20 to $87 \%$ versus the control. As expected, 7 days after emergence, the transcript level of $\mathrm{Vg}$ was also significantly lower in the viruliferous females $(F=$ $24.599, \mathrm{df}=4, P=0.008$ ) based on the Western blotting assay with Vg-specific antibodies (Fig. 4C). Taken together, these results

Table 1. Life-history table of viruliferous and nonviruliferous Recilia dorsalis infected with the virus through maternal inheritance

\begin{tabular}{lcc}
\hline Parameter $^{\mathrm{t}}$ & Nonviruliferous & Viruliferous \\
\hline $\mathrm{No}$ & 100 & 100 \\
$\mathrm{Su}_{1-5}(\%)^{\mathrm{u}}$ & $74.84 \pm 2.16 \mathrm{a}$ & $55.34 \pm 1.98 \mathrm{~b}$ \\
$\mathrm{Emr}(\%)^{\mathrm{v}}$ & $95.35 \pm 1.01 \mathrm{a}$ & $82.83 \pm 1.15 \mathrm{~b}$ \\
$\mathrm{Fr}(\%)^{\mathrm{w}}$ & $51.43 \pm 1.55 \mathrm{a}$ & $50.44 \pm 2.56 \mathrm{a}$ \\
$\mathrm{Cr}(\%)^{\mathrm{x}}$ & $86.12 \pm 1.25 \mathrm{a}$ & $92.26 \pm 1.03 \mathrm{~b}$ \\
$\mathrm{Fy}$ & $178.83 \pm 15.68 \mathrm{a}$ & $96.38 \pm 4.94 \mathrm{~b}$ \\
$\mathrm{Ecr}(\%)^{\mathrm{z}}$ & $67.93 \pm 1.93 \mathrm{a}$ & $65.57 \pm 1.99 \mathrm{a}$ \\
$\mathrm{Nt}$ & $3,839.52$ & $1,348.05$ \\
$\mathrm{I}$ & 38.40 & 13.48 \\
\hline
\end{tabular}

${ }^{\mathrm{t}}$ Abbreviations: $\mathrm{No}=$ number of individuals in the initial population, $\mathrm{Su}_{1-5}=$ survival rate from neonate to fifth-instar nymph before adult emergence, Emr $=$ emergence rate, $\mathrm{Fr}=$ ratio of females to males, $\mathrm{Cr}=$ rate of mating success, $\mathrm{Fy}=$ fecundity (eggs per female), $\mathrm{Ecr}=$ eclosion rate, $\mathrm{Nt}=$ predicted number of offspring, and $\mathrm{I}=$ population trend index. Mean \pm standard error is the mean of three replicates with standard error. Different letters in the same row indicate a significant difference based on Tukey's honestly significant difference test (at the level $P=0.05$ ).

u One-way analysis of variance (ANOVA): $F=236.94, \mathrm{df}=4, P=0.000$.

v One-way ANOVA: $F=26.049, \mathrm{df}=4, P=0.002$

w One-way ANOVA: $F=0.361, \mathrm{df}=4, P=0.58$.

x One-way ANOVA: $F=8.795, \mathrm{df}=4, P=0.041$.

y One-way ANOVA: $F=22.205, \mathrm{df}=4, P=0.009$

${ }^{\mathrm{z}}$ One-way ANOVA: $F=1.243$, df $=4, P=0.327$. indicated that RGDV significantly reduced $R$. dorsalis fecundity by altering levels of $\mathrm{Vg}$ transcript and protein product.

Monitoring VR in the natural $R$. dorsalis population of Guangdong. Variation in the VR of $R$. dorsalis from the two counties over a 2-year period revealed a declining trend in the overwintering generation (Fig. 5). In general, whether VR was high or low, the VR of the first and second generation insects was lower than that of the previous generation. It is still worth mentioning that a higher VR in an overwintering generation was linked to a lower VR in the next generation. Thus, the lower VR of first- and second-generation insects compared with those in the previous overwintering generation may be attributed to the adverse effects of viral infection.

\section{Discussion}

RGDV can be transmitted vertically from female parent to offspring via maternal inheritance. In this study, to eliminate any potential indirect effects on the vector from infected plants, we first produced a RGDV-positive $R$. dorsalis population that was infected through maternal inheritance. We provide clear evidence to show that RGDV infection directly prolonged the nymphal stages of leafhoppers, shortened adult longevity, reduced survival rates of nymphs, and decreased adult fecundity (Figs. 2 and 3; Table 1), which was inconsistent with Tomato yellow leaf curl China virus (Jiu et al. 2007). A previous study indicated that nymphal WBPH not only have a higher efficiency of acquisition virus but also have a higher efficiency of transmission than adults (Tu et al. 2013). These differences were similar to our results, suggesting that the immunity or metabolism of insect vector might affect the propagation of RGDV. It also appears to affect the coevolutionary aspects of virus-vector interactions. Thus, a longer nymphal period may benefit the virus, in terms
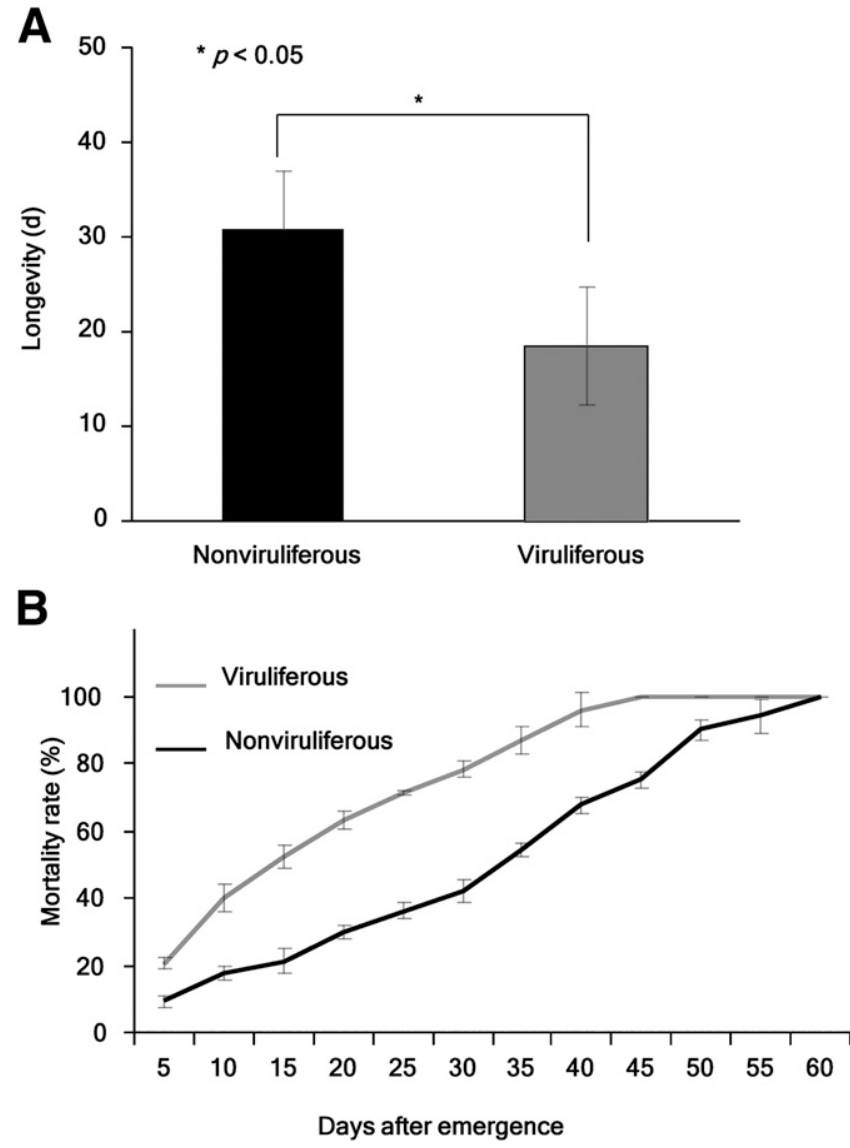

Fig. 3. Direct effects of Rice gall dwarf virus on the longevity of viruliferous versus nonviruliferous Recilia dorsalis adults. Each histogram bar represents the mean ( \pm standard error) of three replicates; means were compared using Tukey's honestly significant difference test (at the level $P=0.05$ ). A, Longevity (from emergence of adult until death) and $\mathbf{B}$, mortality of adults. 
of acquisition and transmission by the nymphs, but RGDV infection generally limited increase of the $R$. dorsalis population and hindered virus transmission. Some studies indicate that changes in plant physiology can happen immediately after pathogen inoculation (Luan et al. 2013; Stout et al. 2006). Thus, in our study, even replacing the very young seedlings on a daily basis may not completely eliminate potential plant effects on the vector. However, we had eliminated most potential plant effects (RGDV-infected rice) on the vector and demonstrated that the infection of RGDV had a direct adverse effect on the fitness of its insect vector.

RGDV can propagate well and circulate in the body of $R$. dorsalis (Zheng et al. 2015). Our previous findings showed that RGDVcoated mitochondria are located near the viroplasm, the site of viral replication and assembly, suggesting that mitochondria might support the energy demands of viral propagation in the insect vector, and that virus-coated mitochondria become degraded at the late stage of viral replication (Wei et al. 2011). Furthermore, RGDV particles are also directly associated with the cytoskeleton, including microtubules, vimentin intermediate filaments, and actin, which facilitates viral intra- or intercellular spread among insect vector cells (Chen et al. 2013; Wei et al. 2009). Thus, RGDV would directly remodel and utilize a variety of cellular structures and pathways for efficient viral propagation in its insect vector, which may affect the normal growth and development of leafhoppers. This present evidence apparently confirms our previous observation that RGDV infection may adversely affect vectors at the cellular level. In addition, we have found that RGDV infection remarkably altered the expression profile of $R$. dorsalis transcriptome (unpublished data). Notably, the transcriptome indicated that ecdysone and juvenile hormones, which are important for regulating molting and metamorphosis in insects (Jindra et al. 2013; Xi et al. 2015), were upregulated in viruliferous nymphs compared with control nymphs. Based on this finding,
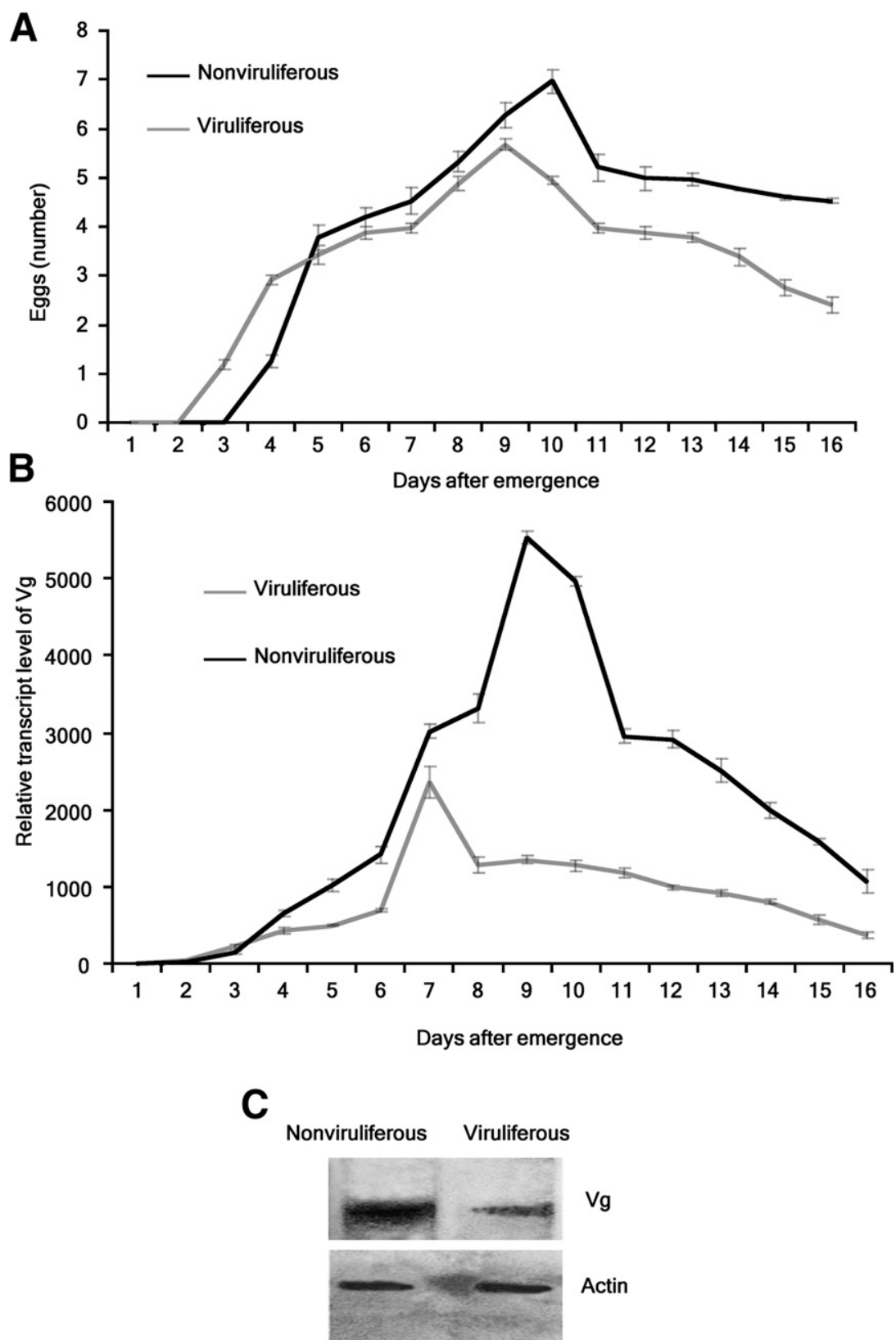

Fig. 4. Direct effects of Rice gall dwarf virus on fecundity of viruliferous versus nonviruliferous adult Recilia dorsalis adults. A, Oviposition dynamics (number of eggs laid by each female per day) based on three replicates. B, Quantitative reverse-transcription polymerase chain reaction analysis of vitellogenin ( $\mathrm{Vg}$ ) expressed in females. The expression level of $\mathrm{Vg}$ genes was normalized relative to $\beta$-actin transcript. $\mathrm{Vg}$ was expressed at a background level in the nonviruliferous 1-day-old adult (24 h postemergence). $\mathrm{C}$, Western blotting assay for $\mathrm{Vg}$ in females. Means were compared using Tukey's honestly significant difference test (at the level $P=0.05$ ). 
combined with the observation that viruliferous nymphs frequently died during molting, we suggest that this change might result in the longer nymphal stages and lower survival rate of nymphs after viral infection. On the other hand, the immune response-related genes such as autophagy and apoptosis were significantly up- or downregulated in the viruliferous expression profile. We infer that the observed developmental delay in viruliferous insects may result from the cost of mounting an immune response against RGDV propagation. Thus, the adverse effects of RGDV infection on $R$. dorsalis may be caused by the damage in functionally relevant tissues and organs or the altered expression of some related genes.

Our investigation revealed a declining trend in the overwintering VR of a natural viruliferous $R$. dorsalis (Fig. 5). In general, the incidence of rice gall dwarf disease is low in winter fields of Alopecurus aequalis, which is the primary habitat of overwintering $R$. dorsalis in Luoding and Xingning Counties (Xie et al. 1985). Influenced by the low temperatures, acquisition of the virus from infected plants by nonviruliferous insects is almost blocked in the winter. In this case, without an effective supplementary virus source, offspring derived from viruliferous parents are the main viral source. Our results suggest that RGDV infection directly affected the fecundity of adult insects (Fig. 4; Table 1), possibly through altering levels of $\mathrm{Vg}$ transcript and protein product. Furthermore, viruliferous insects were challenged either by abiotic stress (low temperatures and so on) or by biotic stress factors (infection with parasitic insects). This stress

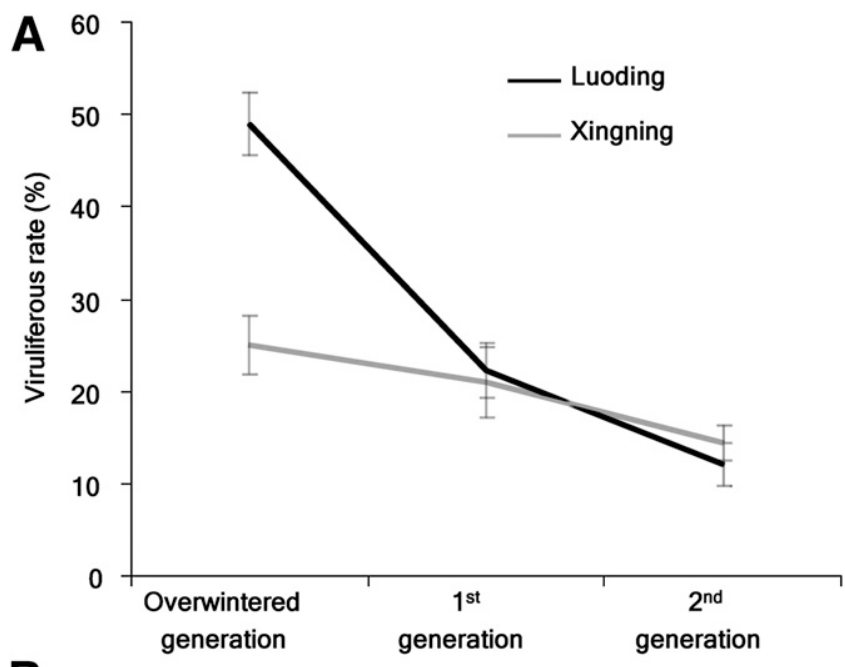

B

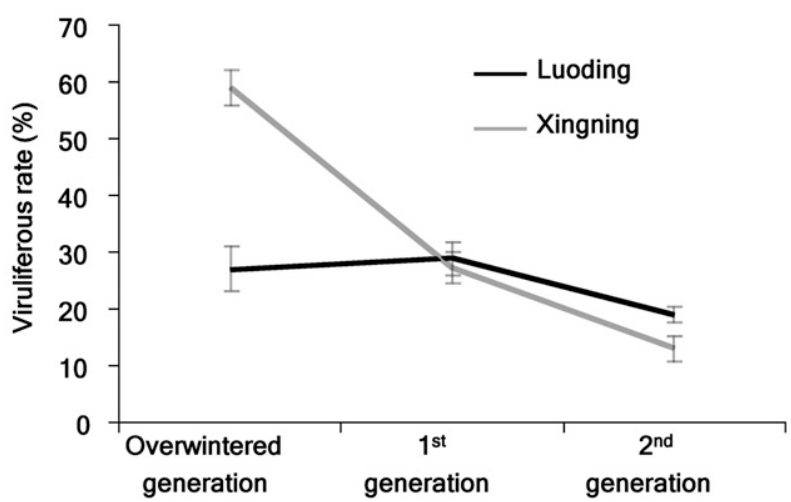

Fig. 5. Monitoring of viruliferous rate (VR) fluctuations among generations of natural Recilia dorsalis populations in Guangdong. All data shown are mean values ( \pm standard error). Means were compared using repeated-measure analysis of variance (ANOVA) with group-VR interaction (at the level $P=0.05$ ). A, VR results for Luoding and Xingning Counties in 2013 to 2014. Repeated-measure ANOVA: Xingning was used as control, significantly different compared with controls, group-VR interaction, $F=8.339, \mathrm{df}=2$, $P=0.011$. B, VR fluctuations for both counties in 2014 to 2015. Repeated-measure ANOVA: Luoding was used as control, significantly different compared with controls, group-VR interaction, $F=8.949$, df $=2, P=0.004$ would result in lower survival rates of viruliferous populations compared with nonviruliferous populations (de Oliveira et al. 2014). These results, together with our evidence that "middle-aged" viruliferous adults are more likely to die, suggest that the ultimate result is a decline in the viruliferous $R$. dorsalis population. Thus, the dynamics of the overwintering VR in Guangdong Province further support our conclusion that there is a direct adverse effect of RGDV infection on the fitness of $R$. dorsalis. This finding might also explain the intermittent epidemics of rice gall dwarf disease in Guangdong over the past 5 years. Generally, in that province, we found a rapid decrease in RGDV occurrence immediately after a high prevalence in the previous year. Similar interactions have also been documented between SRBSDV and its vector, S. furcifera (Tu et al. 2013). Further investigation is needed to focus on whether the intermittent epidemics of plant diseases caused by persistent-propagative plant viruses are related to the direct adverse effects of their infection on insect vectors.

Under natural conditions in the field, plant viruses such as tospoviruses, tenuiviruses, rhabdoviruses, and reoviruses are transmitted by their respective insect vectors in a persistent-propagative manner (Ammar et al. 2009; Hogenhout et al. 2008). These viruses have evolved to be well-adapted for persistent infection and maintenance in their vectors, in order to facilitate highly efficient viral transmission. However, our evidence shows that the propagation of a plant virus in its vector also has a direct, adverse impact on vector biology. How to modulate the excessively negative impact of viral infection on the viability of insects is the key factor driving viral transmission via insect vectors. Recently, we demonstrated that knockdown of the expression of core components of the RNAi antiviral pathways Dicer2 and Argonaute2 reduced the survival rate and lifespan of S. furcifera infected with SRBSDV (Lan et al. 2015). Thus, the insect RNAi antiviral pathway may play a crucial role in controlling viral transmission by preventing the excessive accumulation of plant viruses in insect vectors, thereby protecting them from the negative impact of these viruses. Further investigation is needed to verify whether the RNAi antiviral pathway also plays a key role in preventing excessive RGDV accumulation in $R$. dorsalis.

\section{Acknowledgments}

This research was supported by the National Natural Science Foundation of China (31130044, 3140171, and 31501603), the National Basic Research Program of China (2014CB138400), the National Science Foundation for Outstanding Youth (31325023), the Specialized Research Fund for the Ministry of Agriculture (201303021), and the Natural Science Foundation of Fujian Province (K51310859).

\section{Literature Cited}

Ammar, E. D., Tsai, C. W., Whitfield, A. E., Redinbaugh, M. G., and Hogenhout, S. A. 2009. Cellular and molecular aspects of rhabdovirus interactions with insect and plant hosts. Annu. Rev. Entomol. 54:447-468.

Belliure, B., Janssen, A., Maris, P. C., Peters, D., and Sabelis, M. W. 2005. Herbivore arthropods benefit from vectoring plant viruses. Ecol. Lett. 8:70-79.

Chen, H. Y., Zheng, L. M., Jia, D. S., Zhang, P., Chen, Q., Liu, Q. F., and Wei, T. Y. 2013. Rice gall dwarf virus exploits tubules to facilitate viral spread among cultured insect vector cells derived from leafhopper Recilia dorsalis. Front. Microbiol. 4:206.

Chen, H. Y., Zheng, L. M., Mao, Q. Z., Liu, Q. F., Jia, D. S., and Wei, T. Y. 2014a Development of continuous cell culture of brown planthopper to trace the early infection process of oryzaviruses in insect vector cells. J. Virol. 88:4265-4274

Chen, Q., Wang, H. T., Ren, T. Y., Xie, L., and Wei, T. Y. 2015. Interaction between non-structural protein Pns10 of Rice dwarf virus and cytoplasmic actin of leafhoppers is correlated with insect vector specificity. J. Gen. Virol. 96:933-938.

Chen, Y., Zhang, J., Qin, X. W., Liu, J., Liu, Q., and Zhang, R. J. 2014b. Sublethal effects of Virtako ${ }^{\mathrm{TM}}$ on life table parameters and wing formation of the brown planthopper (Homoptera: Delphacidae). J. Entomol. Sci. 48:1-10.

Deangelis, J. D., Sether, D. M., and Rossignol, P. A. 1993. Survival, development, and reproduction in western flower thrips (Thysanoptera: Thripidae) exposed to Impatiens necrotic spot virus. Environ. Entomol. 22:1308-1312.

de Oliveira, C. F., Long, E. Y., and Finke, D. L. 2014. A negative effect of a pathogen on its vector? A plant pathogen increases the vulnerability of its vector to attack by natural enemies. Oecologia 174:1169-1177.

Fan, H. Z., Zhang, S. G., He, X. Z., Xie, S. D., Liu, C. Z., Zhou, L. G., Liu, X. R., and Zhu, D. 1983. Rice gall dwarf virus-A new virus disease epidemic in the west of Guangdong Province of south China. Acta Phytopathol. Sin. 13:1-6.

Fereres, A., Lister, R. M., Araya, J. E., and Foster, J. E. 1989. Development and reproduction of the English grain aphid (Homoptera, Aphididae) on wheat cultivars infected with Barley yellow dwarf virus. Environ. Entomol. 18:388-393. 
Fiebig, M., Plehling, H. M., and Borgemeister, C. 2004. Barley yellow dwarf virus, wheat, and Sitobion avenae: A case of trilateral interactions. Entomol. Exp. Appl. 110:11-21.

Guo, J. Y., Dong, S. Z., Yang, X. L., Cheng, L., Wan, F. H., Liu, S. S., Zhou, X. P., and Ye, G. Y. 2012. Enhanced vitellogenesis in a whitefly via feeding on a begomovirus infected plant. PLoS One 7:e43567.

Hogenhout, S. A., Ammar, E. D., Whitfield, A. E., and Redinbaugh, M. G. 2008. Insect vector interactions with persistently transmitted viruses. Annu. Rev. Phytopathol. 46:327-359.

Inoue, H., and Omura, T. 1982. Transmission of rice gall dwarf virus by the green rice leafhopper. Plant Dis. 66:57-59.

Jia, D. S., Chen, H. Y., Zheng, A. L., Chen, Q., Liu, Q. F., Xie, L. H., Wu, Z. J., and Wei, T. Y. 2012. Development of an insect vector cell culture and RNA interference system to investigate the functional role of fijivirus replication protein. J. Virol. 86:5800-5807.

Jindra, M., Palli, S. R., and Riddiford, L. M. 2013. The juvenile hormone signaling pathway in insect development. Annu. Rev. Entomol. 58:181-204.

Jiu, M., Zhou, X. P., Tong, L., Xu, J., Yang, X., Wan, F. H., and Liu, S. S. 2007. Vector-virus mutualism accelerates population increase of an invasive whitefly. PLoS One 2:e182.

Lan, H. H., Zhang, L. H., Liu, Y. Y., Chen, H. Y., Jia, D. S., Chen, Q., and Wei, T. Y. 2015. An RNA interference pathway modulates the persistent infection of Southern rice black-streaked dwarf virus in insect vector, Sogatella furcifera. Chin. Sci. Bull. 60:1361-1369.

Li, S., Wang, S. J., Wang, X., Li, X. L., Zi, J. Y., Ge, S. S., Cheng, Z. B., Zhou, T., Ji, Y. H., Deng, J. H., Wong, S. M., and Zhou, Y. J. 2015. Rice stripe virus affects the viability of its vector offspring by changing developmental gene expression in embryos. Sci. Rep. 5:7883.

Luan, J. B., Yao, D. M., Zhang, T., Walling, L. L., Yang, M., Wang, Y. J., and Liu, S. S. 2013. Suppression of terpenoid synthesis in plants by a virus promotes its mutualism with vectors. Ecol. Lett. 16:390-398

Mao, Q. Z., Zheng, S. L., Han, Q. M., Chen, H. Y., Ma, Y. Y., Jia, D. S., Chen, Q., and Wei, T. Y. 2013. New model for the genesis and maturation of viroplasms induced by fijiviruses in insect vector cells. J. Virol. 87: 6819-6828.

McKenzie, C. L. 2002. Effect of Tomato mottle virus (ToMoV) on Bemisia tabaci biotype B (Homoptera: Aleyrodidae) oviposition and adult survivorship on healthy tomato. Fla. Entomol. 85:367-368.

Morinaka, T., Putta, M., Chettanachit, D., Parejarearn, A., Disthaporn, S., Omura, T., and Inoue, H. 1982. Transmission of rice gall dwarf virus by cicadellid leafhoppers Recilia dorsalis and Nephotettix nigropictus in Thailand. Plant Dis. 66:703-704.

Nakasuji, F., and Kiritani, K. 1970. III-effects of rice dwarf virus upon its vector, Nephotettix cincticeps Uhler (Hemiptera: Deltocephalidae), and its significance for changes in relative abundance of infected individuals among vector populations. Appl. Entomol. Zool. (Jpn.) 5:1-12.

Navas-Castillo, J., Fiallo-Olivé, E., and Sánchez-Campos, S. 2011. Emerging virus diseases transmitted by whiteflies. Annu. Rev. Phytopathol. 49:219-248.

Ng, J. C. K., and Falk, B. W. 2006. Virus-vector interactions mediating nonpersistent and semipersistent transmission of plant viruses. Annu. Rev. Phytopathol. 44:183-212.
Omura, T., Inoue, H., Morinaka, T., Saito, Y., Chettanachit, D., Putta, M., Parejarearn, A., and Disthaporn, S. 1980. Rice gall dwarf virus, a new virus disease. Plant Dis. 64:795-797.

Rubinstein, G., and Czosnek, H. 1997. Long-term association of tomato yellow leaf curl virus with its whitefly vector Bemisia tabaci: Effect on the insect transmission capacity, longevity and fecundity. J. Gen. Virol. 78:2683-2689.

Stout, M. J., Thaler, J. S., and Thomma, B. P. 2006. Plant-mediated interactions between pathogenic microorganisms and herbivorous arthropods. Annu. Rev. Entomol. 51:663-689.

Tu, Z., Ling, B., Xu, D., Zhang, M. X., and Zhou, G. H. 2013. Effects of Southern rice black-streaked dwarf virus on the development and fecundity of its vector Sogatella furcifera. Virol. J. 10:145.

Wang, H., Xu, D., Pu, L. L., and Zhou, G. H. 2014. Southern rice black-streaked dwarf virus alters insect vectors' host orientation preferences to enhance spread and increase Rice ragged stunt virus co-infection. Phytopathology 104:196-201.

Wei, T. Y., Miyazaki, N., Uehara-Ichiki, T., Hibino, H., Shimizu, T., Netsu, O., Kikuchi, A., Sasaya, T., Iwasaki, K., and Omura, T. 2011. Three dimensional analysis of the association of viral particles with mitochondria during the replication of Rice gall dwarf virus. J. Mol. Biol. 410:436-446.

Wei, T. Y., Uehara-Ichiki, T., Miyazaki, N., Hibino, H., Iwasaki, K., and Omura, T. 2009. Association of Rice gall dwarf virus with microtubules is necessary for viral release from cultured insect vector cells. J. Virol. 83:10830-10835.

Whitfield, A. E., Falk, B. W., and Rotenberg, D. 2015. Insect vector-mediated transmission of plant viruses. Virology 479-480:278-289.

Wu, W. J., Wang, Y., Huang, H. J., Bao, Y. Y., and Zhang, C. X. 2012. Ecdysone receptor controls wing morphogenesis and melanization during rice planthopper metamorphosis. J. Insect Physiol. 58:420-426.

Xi, Y., Pan, P. L., Ye, Y. X., Yu, B., Xu, H. J., and Zhang, C. X. 2015. Chitinase-like gene family in the brown planthopper, Nilaparvata lugens. Insect Mol. Biol. 24 $29-40$.

Xie, L. H., and Lin, Q. Y. 1984. Progress in the research of virus diseases of rice in China. Sci. Agric. Sin. 6:58-64.

Xie, S. D., Zhou, L. G., Liu, C. Z., Zhang, S. G., Fan, H. Z., and Liu, X. R. 1985. On the overwintering of the rice gall dwarf virus in Guangdong Province. Acta Phytopathol. Sin. 15:211-216.

Xu, H., He, X., Zheng, X., Yang, Y., Tian, J., and Lu, Z. 2014. Southern rice blackstreaked dwarf virus (SRBSDV) directly affects the feeding and reproduction behavior of its vector, Sogatella furcifera (Horváth) (Hemiptera: Delphacidae). Virol. J. 11:55.

Yoshida, S., Forno, D. A., and Gomez, K. A. 1976:Pages 61-64 in: Laboratory Manual for Physiological Studies of Rice, 3rd ed. International Rice Research Institute, Manila, Philippines.

Zar, J. H. 1996. Biostatistical Analysis, 3rd ed. Commentaries 859. Prentice-Hall, London.

Zhang, J., Zheng, X., Chen, Y. D., Hu, J., Dong, J. H., Su, X. X., and Zhang, Z. K. 2014. Southern rice black-streaked dwarf virus infection improves host suitability for its insect vector, Sogatella furcifera (Hemiptera: Delphacidae). J. Econ. Entomol. 107:92-97.

Zheng, L. M., Chen, H. Y., Liu, H. M., Xie, L. H., and Wei, T. Y. 2015. Assembly of viroplasms by viral nonstructural protein Pns9 is essential for persistent infection of rice gall dwarf virus in its insect vector. Virus Res. 196:162-169. 